\title{
Student well-being in Veterinary Sciences: Implications for student support and career agility
}

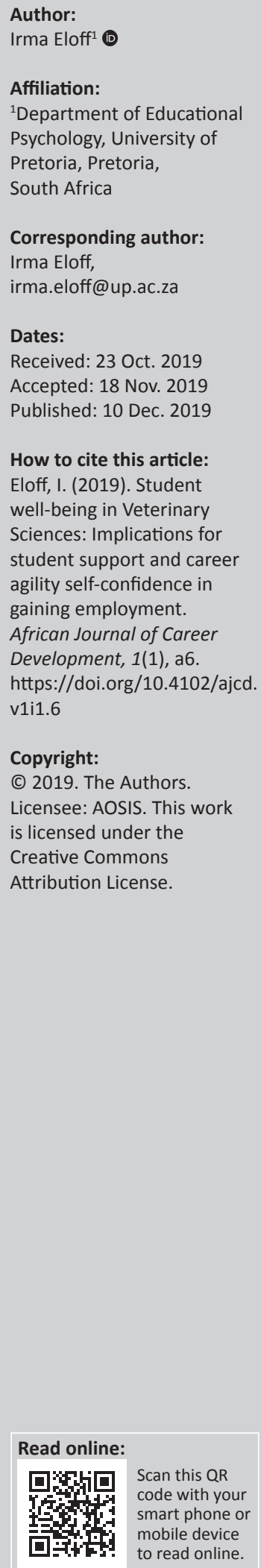

This case study investigates the factors that support and hinder the well-being of undergraduate students in Veterinary Sciences. The study aims to provide textured, nuanced and in-depth qualitative perspectives on the well-being of veterinary science students. The study aims to supplement the growing body of quantitative studies that indicate substantive concerns about the psychological well-being of students in Veterinary Sciences. The study utilised face-to-face interviews $(n=78)$ and an in-depth focus group interview $(n=9)$ within the bounded system of a Faculty of Veterinary Science at a large, urban university. Findings indicate that the wellbeing of students in Veterinary Sciences is supported by students actively taking ownership of their psychological well-being, and the presence of animals in their social and personal lives. The study also shows that a sense of isolation, both socially and geographically, may be hindering students' well-being.

Keywords: Veterinary Sciences; undergraduate; student well-being; student support; career agility.

\section{Introduction}

The mental health and well-being of students of Veterinary Sciences have received growing attention in recent years (Killinger et al. 2017; Reisbig et al. 2012). Studies report up to one-third of veterinary medical students, surveyed during the first and second semesters, with depression levels above the clinical cut-off and up to $15 \%$ of some student samples experiencing an increase in depression of at least one standard deviation (1 SD) (Hafen et al. 2008). Along similar lines, a 4-year cohort study (Siqueira Drake et al. 2012) in the US context has pointed out that a large number of veterinary medical students experience clinical levels of anxiety and depression across all 4-year cohorts. Findings from this study indicate elevated scores on anxiety and depression, and specifically students in their second and third years had the highest anxiety and depression scores. Stressors described to explain the symptoms of depression and anxiety included perceived physical health, difficulty fitting in, heavy workloads, unclear expectations and homesickness.

Other studies indicate that some veterinary science students with higher-functioning relationships are indeed more likely to report fewer depressive symptoms, and lower stress associated with balancing their university and home lives, but then these same students are simultaneously experiencing more stress from falling behind academically (Hafen, Ratcliffe \& Rush 2013). A need for deeper understandings about the well-being of students of Veterinary Sciences seems evident.

\section{Background to the current study}

Most of the studies that have investigated the mental health and well-being of students in Veterinary Sciences utilise psychometric and quantitative measures to collect data. The current study set out to explore qualitative aspects to potentially provide more in-depth insights into the dynamics and complexities at play. Veterinary Science as both science and profession is linked to several of the sustainable development goals, and therefore the well-being of future veterinarians is of concern for all.

\section{Objectives of the study}

The study is aimed to answer the following question:

Which factors support and hinder the well-being of veterinary science students?

The framing of the question to explore the factors that support and hinder well-being was deliberate. It was framed to provide nuanced understandings that could potentially assist the future 
development of support programmes for students in Veterinary Sciences in order to enhance their well-being. The study also adopted an open-ended format to allow authentic responses on student well-being that would illuminate the trends evident in quantitative studies of veterinary science students.

\section{Research setting}

The study was conducted at the Faculty of Veterinary Science, University of Pretoria. It is the only faculty responsible for the training of veterinarians and veterinary nurses in the country. The faculty is ranked highly on numerous international rankings. It is situated on the Onderstepoort Campus of the University of Pretoria, with a world-class animal hospital and state-of-the-art facilities in Veterinary Sciences.

\section{Research methodology}

An instrumental case study was conducted to investigate the well-being of veterinary science students at the University of Pretoria. Face-to-face interviews $(n=78)$ and an in-depth focus group interview (time 1:06:08; $n=9$ ) were conducted with undergraduate students of veterinary science. For face-to-face interviews, fieldworkers approached students on campus to ask the following question: 'which factors support your well-being at the University of Pretoria?' Responses were taken down manually on paper. Biographic data of respondents were also taken down alongside the written responses. Afterwards, all written responses were transferred to electronic format for the purpose of data analysis. Interviews were conducted in the first semester of the academic year. The focus group interview was conducted by an experienced researcher in the helping professions (e.g. social work) with a group of undergraduate veterinary science students $(n=9)$. The focus group discussion was audio-recorded and transcribed. Data from both the face-to-face interviews and focus group discussion were analysed by means of theme analysis.

\section{Participants}

All the participants $(n=78)$ of this study were undergraduate students at the Faculty of Veterinary Science (Table 1). Most students $(n=67)$ were enrolled for a degree in Veterinary Science (BVSc) and some $(n=11)$ were enrolled for a diploma in veterinary nursing. The age of participants ranged from 18 to 34 years, and the mean age was 22.6 years. The modal age was 24 years. Most of the participants $(n=37)$ indicated English as their first language, 27 students indicated Afrikaans, 11 students indicated another African language and 3 students indicated 'other'.

All focus group participants $(n=9)$ were South African citizens and undergraduate students at the Faculty of Veterinary Science, doing BVSc (Table 2). Their ages ranged between 21 and 40 years, with one missing value (unknown).
TABLE 1: Characteristics of participants (interview group; $n=78$ ).

\begin{tabular}{lcc}
\hline Characteristic & Frequency & \% \\
\hline Gender & 23 & 29.5 \\
Male & 55 & 70.5 \\
Female & & \\
Citizenship & 71 & 91.0 \\
South African citizen & 4 & 5.1 \\
SADC country & 1 & 1.2 \\
Other African country & 2 & 2.5 \\
Non-African & & \\
Ethnicity $\dagger$ & 18 & 23.1 \\
Black people & 43 & 55.1 \\
White people & 12 & 15.4 \\
Indian people & 5 & 6.4 \\
Mixed-race people & & \\
\hline
\end{tabular}

SADC, Southern African Development Community.

$\dagger$, Ethnicity was captured as a biographical variable within the ethical application process for the study. The study, however, acknowledges race as a social construct.

TABLE 2: Characteristics of participants (focus group; $n=9$ ).

\begin{tabular}{lcc}
\hline Characteristic & Frequency & $\%$ \\
\hline Gender & 4 & 44.4 \\
Male & 5 & 55.6 \\
Female & & \\
Citizenship & 9 & 100 \\
South African citizen & & \\
Ethnicity & 3 & 33.3 \\
Black people & 2 & 22.2 \\
White people & 3 & 33.3 \\
Indian people & - & \\
Mixed-race people & 1 & 11.1 \\
Others & - & 100 \\
\hline Total & &
\end{tabular}

The mean age of the focus group participants was 24.87 years, with modal ages of 21, 22 and 23 years. Five participants indicated English as their first language, and the remaining four participants each indicated Afrikaans, isiXhosa, Sepedi and Tshivenda as their first language.

\section{Ethical considerations}

The study was conducted as part of a comprehensive student well-being research project at the University of Pretoria. Ethical clearance (GW0180232HS) was obtained from the Ethics Committee of the Faculty of Humanities, as well as the University of Pretoria Survey Organising Committee.

\section{Findings}

The study indicates three main thematic factors that support and hinder the well-being of veterinary science students. Student well-being is supported by the following two factors:

- students actively taking ownership of their own wellbeing

- presence of animals in the social and personal lives of students.

Student well-being is hindered by the following factor:

- a sense of isolation. 
In the next section, each of these thematic factors is discussed by sharing some direct extracts from the data sets. These extracts are illustrative, rather than exhaustive, of the broad theme that has emerged in the data. Some data extracts provide confirmation for some of the themes that have been highlightedin other studies (Hafen et al. 2013; Killinger et al. 2017), but here provide additional nuance at personal level.

\section{Students actively taking ownership of their own well-being}

The data from both interviews and focus group show that students' well-being is supported when students actively take responsibility for their own well-being. Many students show high levels of internal locus of control. They embrace healthy coping strategies that support their studies:

'Sporting activities, Binge watching series. Outings with friends, comfort eating and lots of sleep.' (Interview 20, male, 24 years)

'Balancing academics. Socialising with people who can assist me with academics. Taking time out for myself and away from academics. Exercise to calm down stress during tests or examination.' (Interview 59, male, 21 years)

'Being surrounded by positive people and a good working environment.' (Interview 64, female, 19 years)

'I think, the best part of studying at OP [Onderstepoort] is the fact that we have an amazing campus. There is so much to do here, whether you want to go to the gym, for a swim, play some squash or tennis, everything right here on campus. Staying in res also helps a lot, you can meet up with friends for coffee and discuss whatever is bothering you. OP really helps you have a well-balanced life.' (Interview 16, female, 23 years)

'... the one that stood out for me the most is relationships at the moment, especially because I'm a res student ... I find a great deal of comfort in friends and having that social every two weeks or whatever not even just doing something else just socialising with my peers and the residence takes a great deal of stress off my shoulders so it's relationships.' (Focus Group, response 6)

'I think, it definitely you as an individual need to understand what aspects of your life you need to work on so that you can have a happy life so that school work is balanced with relationship and that is a very ... personal thing, but I think that there should also be facilities to aid you in showing you how to do it, or how to deal with stress, how to deal with anxiety, or if there's maybe somebody that comes to campus and speak once a week on stress and anxiety and so that's I feel like there's a balance between what you should be doing and who can help you to do.' (Focus Group, response 130)

Students take ownership of their own well-being when they purposefully engage in leisure activities, invest in healthy relationships and pro-actively manage their stress levels. This form of personal agency bodes well for the future career agility. Correia et al. (2017) have shown similar findings with students who actively engage in activities that reduce stress and depression.

\section{Presence of animals in the social and personal lives of students}

Perhaps, not surprisingly, the presence of animals is integral to the well-being of the participants in this study, as illustrated below:

'I live off campus with my dog. I exercise at least four times a week. I have a society at the university focused on wildlife. I have three close friends who study with me and we rely on each other. I have a good support structure when life gets hard. I have a good relationship with my parents, boyfriend.' (Interview 8, female, 22 years)

'Daily exercise, weekly training in Jiu-jitsu. Being allowed to walk the campus beagles. Campus being so close to res, no stress about transport. Being given free medical and psychological care. Being given the schedule for the whole year, allowing myself to plan ahead of time.' (Interview 13, female, 20 years)

'Walking the beagles, housemates, staying in South Africa.' (Interview 18, male, 22 years)

'Housemates. International friendships. Walking the beagles at OP. Being a part of multiple clubs. South African culture. Understanding and helpful student peers. Ability to travel on the weekends and explore South Africa.' (Interview 19, female, 23 years)

'Being able to be constantly around animals and like-minded people.' (Interview 60, female, 24 years)

'I am a depressive person, small things get me down. Sleeping makes me feel best. Ultimately, I would go horse riding every day. I see a psychiatrist, a psychologist to help with my issues. My dogs living with me is probably what keeps me going the best.' (Interview 61 , female, 26 years)

\section{A sense of isolation}

While the presence of animals in their lives and actively taking ownership seems to support the well-being of the participants of this study, a sense of isolation seems to be hindering their well-being. The sense of isolation emanates from both geographical isolation from the rest of the university and a psychological sense of isolation for some students, as illustrated below:

'The campus is too isolated from the rest of the university and the academic stress is high, this can decrease well-being, which is why I live off campus. Since moving out, my well-being has improved.' (Interview 8, female, 22 years)

'... they feel isolated right, everyone seems like they coping and they're fine and they having to hide, the ones who can't cope with it - am I even meant to be here, is this where I am supposed to be?' (Focus Group, response 9)

'... and then just the isolation is the environment at OP ... because you're isolated you're almost forced to stay in this environment, so if you stay in res, you constantly surrounded by OP you're constantly by the pressure the competitiveness.' (Focus Group, response 19)

'.... and then if I can add on like the isolation not on the friends but family as well there's a lot of people are not from here.' (Focus Group, response 15) 
'In terms of facilities also we don't have ... main campus has Bookmark has the store for books and stationary and all that our campus doesn't have that.' (Focus Group, response 50)

'... they've kind of been like ... you're a far campus this is gonna be hard ...' (Focus Group, response 105)

\section{Conclusion}

Tailored-support strategies for students studying in Veterinary Sciences seem to be advisable. Findings from this qualitative case study indicate that the integration of animals at social and personal levels could potentially enhance the well-being of students studying in Veterinary Sciences. The study also indicates that increased awareness of personal agency in supporting well-being could be leveraged to optimise their well-being. Developing personal agency in improving well-being at individual level also holds the possibility of contributing to career agility over a lifetime. In addition to developing tailored support for students of Veterinary Sciences during the years of study, active strategies to counter isolation, geographical and personal, also seem to have the potential to improve their well-being.

\section{Acknowledgements}

The fieldwork for the interviews was conducted by students in the helping professions from the University of Pretoria. The focus group was conducted by a researcher from the Department of Social Work at the University of Pretoria, Leanne Jordaan.

\section{Competing interests}

The author has declared that no competing interests exist.

\section{Author's contributions}

I declare that I am the sole author of this research article.

\section{Funding information}

This research was funded by the University of Pretoria.

\section{Data availability statement}

Data from interviews and the focus group are available upon request to the author.

\section{Disclaimer}

The views and opinions expressed in this article are those of the author and do not necessarily reflect the official policy or position of any affiliated agency of the author.

\section{References}

Correia, H.M., Smith, A.D., Murray, S., Polak, L.S., Williams, B., \& Cake, M.A. (2017) The impact of a brief embedded mindfulness-based program for veterinary students. Journal of Veterinary Medical Education, 44(1), 125-133. https://doi. org/10.3138/jvme.0116-026R

Hafen, M., Jr., Ratcliffe, G.C., \& Rush, B.R. (2013). Veterinary medical student wellbeing: Depression, stress, and personal relationships. Journal of Veterinary Medical Education, 40(3), 296-302. https://doi.org/10.3138/jvme.1112-101R

Hafen, M., Jr., Reisbig, A.M., White, M.B., \& Rush, B.R. (2008). The first-year veterinary student and mental health: The role of common stressors. Journal of Veterinary Medical Education, 35(1), 102-109. https://doi.org/10.3138/jvme.35.1.102

Killinger, S.L., Flanagan, S., Castine, E., \& Howard, K.A. (2017). Stress and depression among veterinary medical students. Journal of Veterinary Medical Education, 44(1), 3-8. https://doi.org/10.3138/jvme.0116-018R1

Reisbig, A.M., Danielson, J.A., Wu, T.-F., Hafen, M., Jr., Krienert, A., Girard, D. et al. (2012). A study of depression and anxiety, general health, and academic performance in three cohorts of veterinary medical students across the first three performance in three cohorts of veterinary medical students across the first three
semesters of veterinary school. Journal of Veterinary Medical Education, 39(4), 341-358. https://doi.org/10.3138/jvme.0712-065R

Siqueira Drake, A.A., Hafen, M., Jr., Rush, B.R., \& Reisbig, A.M. (2012). Predictors of anxiety and depression in veterinary medicine students: A four-year cohort examination. Journal of Veterinary Medical Education, 39(4), 322-330. https:// doi.org/10.3138/jvme.0112-006R 